\title{
Thermal Properties of Insulation Boards Made of Tree Bark \& Hemp Residues
}

\section{Konstantinos Ninikas*, George Ntalos}

University of Thessaly, School of Technology, Dep. Of Forestry, Wood Science \& Design, 11 V. Griva str. 43100, Karditsa, Greece

\section{Nicholas Hytiris}

Glasgow Caledonian University, School of Engineering and Built Environment, 70 Cowcaddens Rd, Glasgow G4 OBA, U.K.

\section{Michael Skarvelis}

University of Thessaly, School of Technology, Dep. Of Forestry, Wood Science \& Design, 11 V. Griva str. 43100, Karditsa, Greece

${ }^{*}$ Corresponding author: kninikas@teilar.gr

$\Gamma$ crossef $h$ ttp://dx.doi.org/10.5755/j01.sace.24.1.22125

Two disparate waste materials were mixed to identify the likelihood of constructing insulation boards. Tree bark and Hemp (cannabis) residues were combined in different proportions and with two dissimilar types of glue. The thermal conductivity $(\lambda)$ for all boards was measured. Diverse methods of processing the final boards demonstrated altered thermal properties based also on the different density (low and medium). The results have validated the possibility of exploiting local waste materials to produce an eco-friendly, low priced insulation product with competitive $(\lambda)$ compared to the market products. All materials were collected within a small range to the laboratory $(<100 \mathrm{~km})$. The energy requirements and the carbon footprint of these boards were kept low compared to traditional chemical insulation materials.

Keywords: Thermal insulation properties, waste to energy, wood by-products, tree bark, Cannabis residues.

Domestic buildings are the foremost contributors to carbon emissions (IGT, 2010). In this sector, the highest portion of energy is spent on retaining indoor thermal ease via space heating. Until recently, this was accommodated by massive fossil fuel consumption. This heat energy demand may be reduced by adequately insulating buildings (Mackenzie et al, 2010). However, the trend which comes from political as well as from environmental policies, desires to find alternatives to fossil fuels. The need to exploit waste materials at the highest possible percentage, is a one-way path towards a sustainable and eco-friendly energy approach.

The most commercial insulation products today are based on oil. Switching to more environmentally friendly materials to insulate the dwelling's shell has to be everybody's primary target. The bark protects the layer of cambium of the tree mitigating also the harmful effect of fire (Bauer et al, 2010, Wang - Wangen 2011). A number of products come from tree bark like absorbers and raw material for fertilizers, however, the need for higher valued products is always the ultimate goal for each material (Naundorf et al, 2004).
JSACE $1 / 24$

Thermal Properties of Insulation Boards Made of Tree Bark \& Hemp Residues

Received 2018/12/11

Accepted after revision 2019/02/11

\section{Introduction}

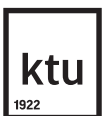

Journal of Sustainable Architecture and Civil Engineering Vol. 1 / No. 24 / 2019 pp. 71-77 DOI 10.5755/j01.sace.24.1.22125 
The tree bark comprises approximately ten percent of any given tree (Britannica). In Greece, the tree bark is considered as a waste by-product with no actual use. Hemp (Cannabis) fibres are also treated as agricultural residues with an additional cost for the producer to dispose of them. The goal of constructing trial composites was to identify the possibility of making insulation boards from waste natural materials originating from a short distance with regards to the manufacturing site. Both are carbon-negative materials.

Tree bark has already been used within a wood-based sandwich panel, thereby proving it's insulation properties (Kawasaki T, Kawai S, 2006). Single layer bark insulation boards have also been constructed in laboratories, demonstrating that bark is a promising new insulation material (Kain et al, 2016). On the other hand, hemp has been used as insulation material together with wood, where the hydrothermal performance was studied. The thermal performance of this board was also competitive with an average thermal transmittance of $0.30 \mathrm{~W} / \mathrm{m}^{2} \mathrm{~K}$ compared to existing commercial oil based insulation panels, (Latif et al, 2015).

The goal of constructing trial composites was to identify the possibility of making insulation boards from waste natural materials originating from a short distance with regards to the manufacturing site. Both are carbon-negative materials.

There is a gap in knowledge in terms of understanding the consistency of the two materials, especially with methyl cellulose glue and how mingling them together results in a relative stiff yet light final composite insulation board.

In the present report, the construction method of the three insulation boards is stated, and their thermal performance is stated.

Methods

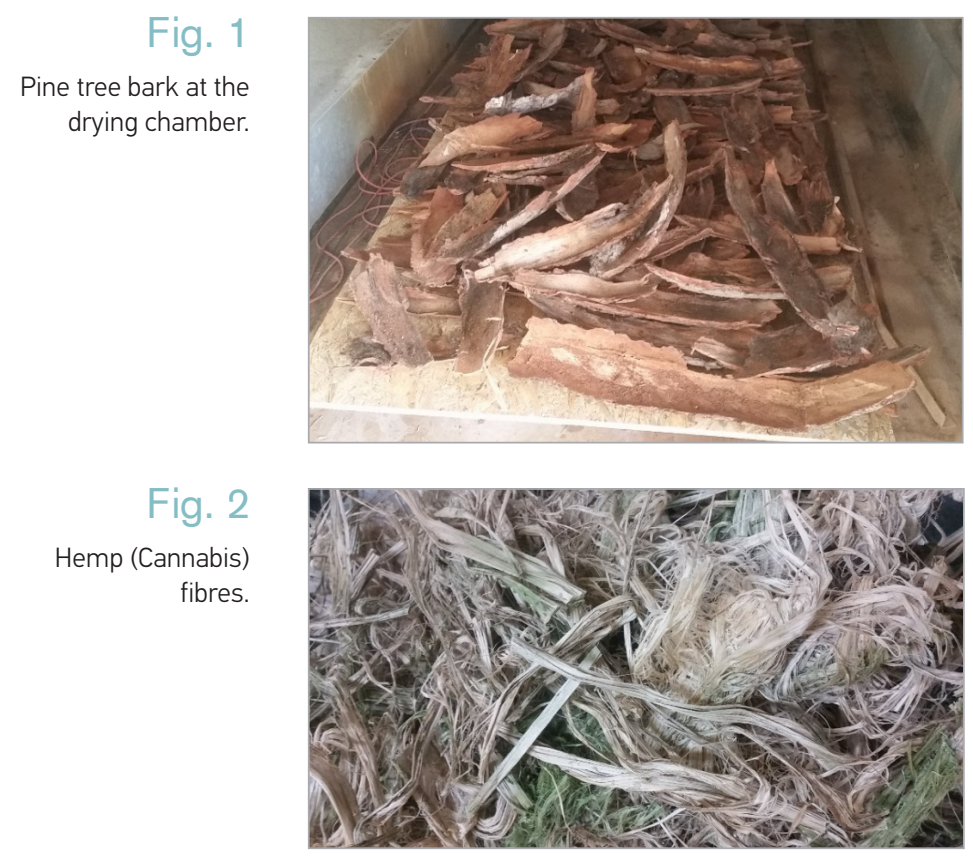
and BS EN 322 - 1993 (Ntalos et al, 2002).
The two by-products (bark - Fig. 1 and cannabis - Fig. 2) were collected in October 2017 from a forest and cropland in Central Greece at a distance $<100 \mathrm{~km}$ from the laboratory in Karditsa, Greece where three insulation boards were constructed

After harvesting, the moisture content measurement was carried out according to DIN:52183/1977

For the "Board A", both ingredients were chipped with a mechanical hammer-mill chipper with a $20 \mathrm{~mm}$ round hole diameter. For the Boards B \& C the bark was chipped with the same mechanical hammer-mill chipper. It was hypothesised that for Boards B \& C, due to the absence of the hot press, the geometry of the cannabis fibres should be such to assist in bonding the two materials together. Thus, the cannabis fibres were manually cut (with a pair of scissors) into approximately $0.10 \mathrm{~m}$ length strips to better bond with the bark. The particles were dried in a hot air dryer from a moisture content of $60 \%$ of the board's weight, down to approximately $5 \%$.

The thickness of all three boards was set to $0.047 \mathrm{~m}$ to fill a $0.095 \mathrm{~m}$ void of a wooden test masonry with an overall wall thickness of $0.160 \mathrm{~m}$. Different methodology was used for the construction of the test board. The three test boards differed in the percentage of the two basic ingredients, the glue type as well as the bonding procedure. 
The "Board A" (Fig. 3) consisted of 80\% bark - 20\% cannabis with a medium-density of approximately $500 \mathrm{Kg} / \mathrm{m}^{3}$ with a urea-formaldehyde glue. A hot press was used to format this insulation board keeping it pressed for 15 min. This was a standard procedure, already undertaken in a number of wood composite products which finally led to a robust and stiff product.

For the low-density boards of $250 \mathrm{Kg} / \mathrm{m}^{3}$ "Board B" and "Board C" which consisted of $70 \%$ bark - 30\% cannabis and $60 \%$ bark - $40 \%$ cannabis respectively (Fig. 4), a non-toxic methyl cellulose glue was used. It is a hydrophilic white powder which dissolved in room temperature water. According to the glue's manufacturer, the solution was of $1.25 \%$ glue (dry powder) and the rest of water. These boards were formatted without the use of a press, remaining within the cast for 2 days.

This solution was stirred for 15 minutes and poured into the two ingredients while they were mixed together before placed in two $0.40 \mathrm{~m} \times 0.40 \mathrm{~m}$ casts (Fig. 5). The casts were covered with flat fiberboards with a light pressure in order to form the final board thickness of $0.047 \mathrm{~m}$. They stayed under pressure for $48 \mathrm{~h}$ at an average room temperature of 23 degrees Celsius before opened.

When the first two boards were taken out of the casts, non-consistent products were witnessed. The boards were not being solidified. However, after a number of attempts with different glue proportions, the $4 \%$ glue mixture, was the one having followed the exact same procedure, which resulted in satisfactory boards with regards to the stiffness and consistency of those two trial boards.

The "box method" based on EN ISO 12667 was used to measure the thermal conductivity value of all three insulation boards. A single box of the El-700 Unit was used (Ei-700) for this purpose (Fig. 6). It is a steady state method. The purpose is to obtain an unidirectional heat flow through the specimen to be tested and to carry out the measurements after the steady state is reached.

This unit can measure the thermal characterisitics of homogeneous or heterogeneous, solid or liquid materials with a comparatively low conductivity $(\lambda<3 \mathrm{~W} / \mathrm{mK})$. The operating temperatures are usually close to the ambient, but the materials can be tested up to about $80^{\circ} \mathrm{C}$. The speciments are $0.27 \mathrm{~m}$

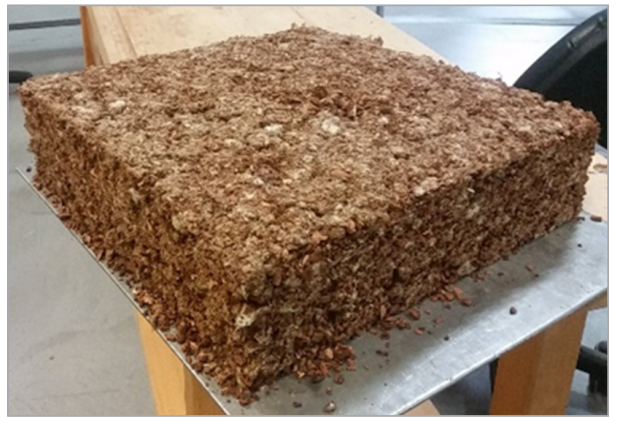

Fig. 3

"Board A"

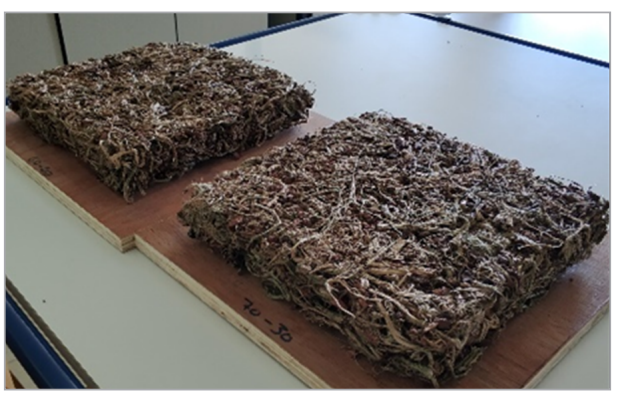

Fig. 4

"Board B" (right) \& "Board C" (left)

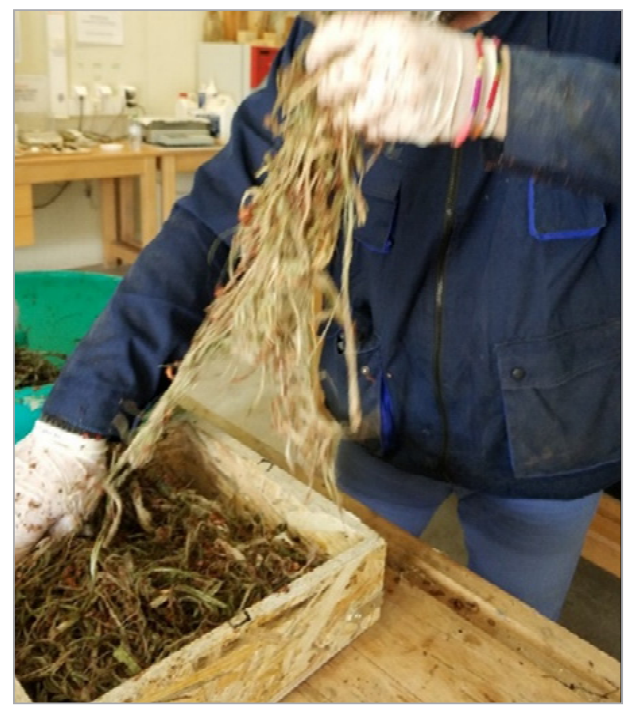

Fig. 5

Positioning the materials into the cast to produce "Board B" and "Board C"

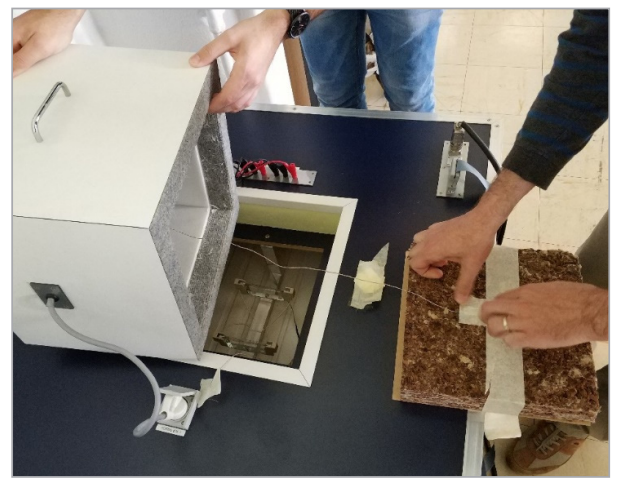

Fig. 6

The El-700 unit "box method" was used for the thermal conductivity measurements 
$X 0.27 \mathrm{~m}$ in size with a thickness range between $0.03 \mathrm{~m}$ and $0.07 \mathrm{~m}$. Two temperature probes have been used, one for the upper ( $\left.T_{\text {uf }}\right)$ and one for the lower ( $\left.T_{\text {If }}\right)$ board's surface temperatures respectively. The room temperature was also recorded. Having the samples within the "box" for approximately 2 hours, the temperature was stabilised and the readings for each probe were noted.

All three test samples had the same size (Width:0.27m, Length:0.27m, Thickness:0.047m) The "box method" produced readings with regard to the thermal conductivity value of all three insulation boards keeping each of them under stable thermal conditions for $24 \mathrm{~h}$..In this steady state the obtained values were based on the following equation:

$$
\lambda=\frac{\boldsymbol{q}_{\text {in }} * \Delta_{x}}{\mathrm{~A} *\left(\boldsymbol{T}_{u f}-\boldsymbol{T}_{l f}\right)}
$$

Where: $\lambda$ - the thermal conductivity value $\left(\mathrm{W} / \mathrm{m}^{*} \mathrm{~K}\right) ; \mathrm{q}_{\text {in }}$ - the heat flux from the indoor environment to the "box" (W); $\Delta_{x}$ - the board's thickness $(\mathrm{m}):(0.047 \mathrm{~m}) ; \mathrm{A}$ - the board's surface $\left(\mathrm{m}^{2}\right)$ : $\left(0.27 \times 0.27=0.0729 \mathrm{~m}^{2}\right) ; T_{\text {uf }}$ - the temperature at the upper surface of the board $\approx 16\left({ }^{\circ} \mathrm{C}\right) ; \mathrm{T}_{\text {lf }}-$ the temperature at the lower surface of the board $\approx 5\left({ }^{\circ} \mathrm{C}\right)$.

Results and discussion

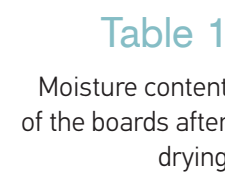

Table 2

Thermal conductivity $(\lambda)$ values of the three insulation boards
The connectivity of two different materials with unlike proportions and the consistency of the final mixed boards with a relative respectable thermal conductivity value was the result of this research. The relative humidity of the three boards, was measured accordingly. The boards were weighted at their final dimensions $(0.27 \mathrm{~m} \times 0.27 \mathrm{~m})$ and directly upon remained at a furnace, at a temperature of $103^{\circ} \mathrm{C}$, until their weight was stable according to the BS EN 322 (Table 1).

After taking readings for each board, the following thermal conductivity values were derived (Table 2).

All three boards resulted in acceptable thermal conductivity values of $0.077 \mathrm{~W} / \mathrm{m}^{*} \mathrm{~K}, 0.078 \mathrm{~W} / \mathrm{m}^{*} \mathrm{~K}$ $\& 0.079 \mathrm{~W} / \mathrm{m}^{*} \mathrm{~K}$. Based on the value $\lambda<1.15 \mathrm{~W} / \mathrm{m}^{*} \mathrm{~K}$ which is considered to be the limit for an appropriate insulation material (JIS, 1994) The $\lambda$ values for the three boards were almost twice as high comparing with commonly used chemical insulation market products. More combinations with regard to the percentages of the two insulation board's materials have been scheduled and expected to be undertaken, in order to improve the insulation capacity of these products. Despite this difference, the pros of these boards are the nature of the basic ingredients which add an environmental friendly product from waste residues. The cost of the two materials used for these

\begin{tabular}{|c|c}
\hline \multicolumn{1}{c|}{ Insulation board } & Moisture content (\%) \\
\hline Board A (80\%TB-20\%CF) & 5.10 \\
\hline Board B (70\%TB-30\%CF) & 5.40 \\
\hline Board C (60\%TB-40\%CF) & 6.15 \\
\hline
\end{tabular}

TB: Tree Bark, CF: Cannabis Fibres

\begin{tabular}{c|c}
\hline \multicolumn{1}{c|}{ Insulation Board } & Thermal conductivity value $(\lambda)\left(\mathrm{W} / \mathrm{m}^{*} \mathrm{~K}\right)$ \\
\hline Board A (80\%TB-20\%CF) & 0.077 \\
\hline Board B (70\%TB-30\%CF) & 0.078 \\
\hline Board C (60\%TB-40\%CF) & 0.079
\end{tabular}

TB: Tree Bark, CF: Cannabis Fibres boards was zero. The bark and the cannabis fibres were provided from two suppliers.

A major issue addressed in this study was the connectivity of two different materials with unlike proportions and the consistency of the final mixed products (insulation boards). The challenge to attempt to combine the tree bark together with the cannabis fibres with different glues, had not been undertaken previously. This has led to interesting results with regards to the final output based on different percentages of the glue 
solution. The use of a medium weight board (approximately $0.47 \mathrm{~g} / \mathrm{cm}^{3}$ ) with a urea-formaldehyde glue ("Board A") has been tried before. However, mixing those two materials together was a novel approach. Nonetheless, the actual challenge was to combine the tree bark together with the cannabis fibres with a methyl cellulose glue as this had not been undertaken previously. The $4 \%$ glue solution, was the limit where from the boards could stand alone with such stiffness to allow them to be positioned within a wooden masonry without breaking into small parts. Thus, the light weight of both boards (approximately $0.24 \mathrm{~g} / \mathrm{cm}^{3}$ ) has a satisfactory value for a future new insulation product.

The different types of glue didn't play a significant role in the thermal performance of the three different boards. It can be seen that the thermal conductivity value for all boards is within a very small range of values.

The energy requirements (energy input) for constructing the three board types were kept low due to the little energy input during the production procedure. The energy input for these boards was broked down into two parts: a. The drying procedure (chamber) which was used for 24 hours to reduce the humidity of the two materials, $b$. The chipping procedure for the mechanical hammer-mill. An additional energy input was necessary for "Board A" using the hot press for 15 minutes to polymerise the urea formaldehyde glue.

Usually, the manufacturing procedure for a typical insulation board, with regards to the energy input during the production line, is immense due to the nature of the basic ingredients (petrol based materials). The production procedure for the three board types is expected to result a more advantageous carbon footprint compared to typical chemical insulation board. The pre-mentioned low energy conditions are basically based on the fact that the two main natural materials require zero energy contrary to foam-based insulation boards.

This paper has focused on the construction as well as on the energy assessment of two mixed insulation boards constructed - in a small scale- from the waste pine tree bark and cropland residues (Cannabis fibres). The heat flux through those boards was simulated with the use of a thermal conductivity measurement unit (EI-700) and the values for all three boards were undertaken. Two different glue types were used. An urea-formaldehyde and a methylcellulose glue. One of the objectives of this study was to produce an eco-friendly product with the waste materials used, to be originated from a close distance $(\leq 100 \mathrm{Km})$ to the production site (laboratory). The limited energy demand for the construction of these borad types is expected to improve the carbon footprint of the insulation board and also to address a financially viable solution for producers who currently direct the residues in landfills with an additional cost. This is a new way of adding value to waste products if will be used for the construction of insulation boards.

In order to declare thermal conductivity for a product, readings for several samples have to be undertaken to present a robust average $\lambda$ value. The measuring device (EI-700 unit) was calibrated according to the manufacturer. In addition, two market composite products (fiberboards of $0.030 \mathrm{~m}$ thickness) were measured at the same device and the received values had a $2 \%$ range deviation (lower value) from their specifications. Therefore, readings were taken only from one board from each category (Board A, Board B, Board C).

The two materials were not layered to form the insulation board. They were mixed together unevenly. In addition to this, the Cannabis fibres length of $0.10 \mathrm{~m}$ proved to be effective for bonding the two materials together (bark and cannabis) and comprise of a robust yet not indestructible composite.

Both were by-products with no use where the harvesting contractors had to bear an additional cost to dispose of them.

The next steps of this study are:

A: to construct more boards with different material's percentages, take readings for the $\lambda$ values to validate and compare those with the current ones. 
B: to identify the exact energy footprint of such an insulation board undertaking an LCA (Life Cycle Assessment) to prove what has been observed during this research, which is a low energy input to construct this board type taking also into account the benefit of using only waste materials from nearby areas.

C: to identify the board's behaviour to fire. An insulation product will usually need to pass British Standard tests regarding fire protection. The two main standards under which such products are assessed are "BS-EN 476-1: Fire tests on building materials and structures" and "BS-EN 13501-1: Fire classification of construction products and building elements". The process for classification under these standards involves a combination of tests designed to assess the product on a range of characteristics, including combustibility, heat levels, flame spread and smoke release.

The use of such waste materials is expected to prove the energy-efficiency for masonry use and also to become economically beneficial to the producers of these products. The impact of using such resources apart from reducing the carbon footprint of the final composite product, plays also a significant role to the LCA (Life Cycle Assessment) due to the nature of the materials (Zampori et al, 2013) and the relatively small distance from the source to the final manufacturing place.

Acknowledgment
The authors would like to thank the University of Applied Sciences (TEI) of Thessaly, for using its testing equipment.

\section{References}

Bauer G., - Speck T., - Blomer J., - Bertling J., - Speck 0. Insulation capability of the bark of trees with different fire adaptation. 2010. J Mater Sci 45:5950-5959. https://doi.org/10.1007/s10853-010-4680-4

Britannica. Bark and Bark products. https://www. britannica.com/science/wood-plant-tissue/Barkand-bark-products [Accessed: 16/01/19].

Greenspec. Insulation materials and their thermal properties. http://www.greenspec.co.uk/building-design/insulation-materials-thermal-properties/. [Accessed: 17/09/18].

EN ISO 12667 European Standard, Thermal Performance of Building Materials and Products-Determination of Thermal Resistance by Means of Guarded Hot Plate and Heat Flow Meter Methods-Products of High and Medium Thermal Resistance, ISO, Geneva, Switzerland, 2001

IGT. Low carbon construction: final report. London: Dept. of Business, Innovation and Skills; 2010.

JIS, Japanese Industrial Standard, Method for thermal transmission properties of thermal insulations. 1994, A1412-1994. Japanese Standards Association Tokyo. Kain G, Barbu M.C, Petutschnigg A. Unasylva, Rome Vol. 67 Iss.247/248 pp 67-75.

Kawasaki T, Kawai S,. Thermal insulation prop- erties of wood-based sandwich panel for use as structural insulated walls and floors. 2006.J Wood Sci, 52: pp 75-83. DOI 10.1007/s10086-005-0720-0. https://doi.org/10.1007/s10086-005-0720-0

Latif E, Ciupala MA, Tucker S, Wijeyesekera DC, Newport DJ, Hygrothermal performance of woodhemp insulation in timber frame wall panels with and without a vapour barrier, Building and Environment (2015), https://doi.org/10.1016/j.buildenv.2015.04.025

Mackenzie F, Pout C, Shorrock L, Matthews A, Henderson J. Energy efficiency in new and existing buildings: comparative costs and $\mathrm{CO} 2$ savings. Bracknell: BRE Press; 2010.

Naundorf W, Wollenberg R, Schubert D. Refinement of bark towards granular filler and insulation materials. Holz als Rohund Werkstoff. 62. 2004. pp 397-404. https://doi.org/10.1007/s00107-004-0514-X

Ntalos G.A., Grigiriou A.H. Characterization and utilization of vine prunings as a wood substitute for particleboard production. Industrial crops and products 16, Elsevier, 2002. pp 59-68.

Wang, G.G., - Wangen S.R.,: Does frequent burning affect longleaf pine (Pinus palustris) bark thickness? 2011. Can. J. For. Res. 41: 1562-1565. 
Zampori L, Dotelli G, Vernelli V. Life cycle assessment of hemp cultivation and use of hemp-based thermal insulator materials. Environ. Sci. Tech- nol.,2013, 47 (13). pp 7413-7420. https://doi. org/10.1021/es401326a

\section{KONSTANTINOS NINIKAS \\ Research associate, teaching staff \\ University of Thessaly, School of Technology, Department of Forestry, Wood Science \& Design, Greece}

Main research area

Energy from waste

\section{Address}

11 V. Griva str. 43100 , Karditsa, Greece. Tel.: + 302441064737 $+306974481086$

E-mail:kninikas@teilar.gr

GEORGE
$\frac{\text { NTALOS }}{\text { Professor }}$
University of Thessaly,
School of Technology,
Department of Forestry,
Wood Science \& Design,
Greece
Main research area
Wood technology, wood
composites, quality
control

Address

11 V. Griva str. 43100 Karditsa, Greece. Tel.: + 302441064707 , $+306932615800$ E-mail: gntalos@teilar.gr

\section{NICHOLAS HYTIRIS \\ MICHALIS SKARVELIS}

Professor

Glasgow Caledonian University, School of Computing, Engineering and the Built Environment, Department of Civil Engineering, Scotland, U.K

Main research area Geotechnics

\section{Address}

Cowcaddens Road, Glasgow, G4 OBA,

Scotland, UK Tel.: + 4401413311593, +4407788445072

E-mail:

N.Hytiris@gcu.ac.uk
Professor

University of Thessaly, School of Technology,

Department of Forestry, Wood Science \& Design, Greece

Main research area

Wood drying

\section{Address}

11 V. Griva str. 43100, Karditsa, Greece.

Tel.: + 302441064743,

$+306944737760$

E-mail:

skarvelis@teilar.gr
About the Authors 